\title{
Prevalence, incidence and characteristics of the metabolic syndrome (MetS) in a cohort of Mexican Mestizo early rheumatoid arthritis patients treated with conventional disease modifying anti-rheumatic drugs: the complex relationship between MetS and disease activity
}

Federico Parra-Salcedo', Irazú Contreras-Yáñez', Daniel Elías-López², Carlos A Aguilar-Salinas² and Virginia Pascual-Ramos ${ }^{1 *}$

\begin{abstract}
Introduction: A higher prevalence of metabolic syndrome (MetS) has been described in rheumatoid arthritis (RA), along with an association with disease activity. Objectives were to describe prevalence of MetS at RA diagnosis in a cohort of Mexican Mestizo early RA patients, and to define a causal association between MetS and disease activity.

Methods: The study population was a prospective cohort. At baseline and at fixed 6-months-intervals, patients had medical evaluations, fasting serum glucose, triglycerides, high-density lipoprotein cholesterol and acute reactant-phase determinations. MetS was defined according to international criteria and body mass index (BMI) $\geq 30 \mathrm{~kg} / \mathrm{m}^{2}$ was used as a surrogate of the waist circumference. The study was approved by the internal review board. Appropriated statistics and Cox regression analysis were used. All statistical tests were two-sided and evaluated the 0.05 significance level.

Results: Up to March 2014, data from 160 patients were analyzed. At baseline, they were more frequently middle-aged females and had moderate to high disease activity. Prevalence of MetS varied from $11.3 \%$ to $17.5 \%$ in patients and was lower to that from matched controls (versus $26.3 \%$ to $30 \%, P \leq 0.01$ ).

Up to last follow-up, 39 patients (34.5\%) developed incidental MetS. In the Cox regression analysis, cumulative disease activity score (DAS) 28 (odds ratio (OR): 1.81, 95\% confidence interval (Cl): 1.346 to 2.433, $P=0.000$ ) and baseline BMl (OR: $1.13,96 \% \mathrm{Cl}: 1.035$ to $1.236, P=0.007$ ) were the only predictors for incidental MetS.

RA patients with incidental MetS accumulated more disease activity and had less frequent remission than their counterparts. Logistic regression analysis showed that incidental MetS (OR: $0.2,95 \% \mathrm{Cl}: 0.01$ to $0.99, P=0.052$ ) and baseline DAS28 (OR: $0.4,95 \% \mathrm{Cl}: 0.2$ to $0.9, P=0.02$ ) were the only predictors for achieving or maintaining sustained ( $\geq 6$ months) remission.
\end{abstract}

Conclusions: MetS prevalence in a cohort of early RA patients was lower than that from matched controls. Cumulative disease activity and higher BMI were risk factors for incidental Mets; higher baseline disease activity and incidental MetS prevented sustained remission. In addition to disease activity, MetS needs to be controlled to impact disease outcomes.

\footnotetext{
* Correspondence: virtichu@gmail.com

'Department of Rheumatology and Immunology, Instituto Nacional de

Ciencias Médicas y Nutrición Salvador Zubirán, Vasco de Quiroga 15, colonia

sección XVI, Tlalpan 14000, México, DF, México

Full list of author information is available at the end of the article
} 


\section{Introduction}

Cardiovascular (CV) disease is the leading cause of death in patients suffering from rheumatoid arthritis (RA) [1-3]. Factors that contribute to increased CV risk are genetic factors, chronic inflammation, traditional $\mathrm{CV}$ risk factors along with disease and treatment-related factors [4-11]. More recently, it has been proposed that metabolic syndrome (MetS) should be added to the list; in the general population, MetS identifies patients at risk of developing coronary heart disease later in life, with a relative risk of 2.7 [12].

MetS refers to a clustering of specific classical CV risk factors, the combination of which is thought to be associated with increased $\mathrm{CV}$ risk beyond the sum of the individual components [13]. The existing literature suggests that inflammatory processes are involved in MetS pathogenesis. Regarding prevalence of MetS in RA, there have been conflicting results but the most recent meta-analysis of 12 observational, cross-sectional studies involving 2,283 Caucasian and Asian RA patients showed a significantly increased prevalence when compared with 4,403 controls [14]. Chung and colleagues found that the frequency of MetS was greater in patients with long-term disease (42\%) than in patients with early arthritis (30\%) [15]; Dao and colleagues confirmed the association between RA and MetS in 105 Vietnamese women with short disease duration and additionally showed that individual components of the MetS, such as hypertension, high-density lipoprotein cholesterol levels and abdominal obesity, were more frequent in RA patients than in their matched controls [16]. Additional studies have found association with some components of the MetS and disease activity [17-19], although the cross-sectional design of the studies prevents identification of causal associations.

In México, data from the National Health and Nutrition Survey 2006 have shown a high prevalence of MetS among adults, ranging from 36.8 to $49.8 \%$ depending on the criteria applied. Notably, MetS was more prevalent among women, among the less educated individuals and among those with lower incomes [20]. Hispanic population-based studies have also shown an increased susceptibility in Mexican adults and confirmed local data [21].

A goal of clinical management in individuals with MetS is to reduce the risk of clinical atherosclerotic disease (and related comorbid conditions), which is a major cause of death in patients with RA [22]. Accordingly, RA patients with such comorbidity need to be identified. Furthermore, the relationship between disease activity and MetS needs to be clarified in order to understand how achievement of major outcomes as sustained remission may further impact on CV mortality. In the literature there is a paucity of data in Latin American countries where both entities, MetS and RA, have distinctive epidemiological, serological and clinical characteristics [23].
The main objectives of the study were: first, to describe the prevalence and characteristics of MetS at RA diagnosis in a cohort of Mexican Mestizo early RA patients and compare these with data from healthy matched controls; and second, to define the relationship between MetS and disease activity. Based on our cohort's characteristics (high disease activity at enrollment, high remission rate after treat-to-target strategy and substantial follow-up [24]), two secondary objectives were established: to investigate MetS as a risk factor to achieve a first sustained remission status; and to determine whether incidental MetS over follow-up impacts disease activity-related outcomes.

\section{Methods}

\section{Setting and study population}

The Early Arthritis Clinic of the Instituto Nacional de Ciencias Médicas y Nutrición Salvador Zubirán was established in February 2004. Patients referred to the clinic had suspicion of RA and symptom duration of less than 12 months. Patients with confirmed recent-onset RA also attend the clinic; in such patients, the time from diagnosis to first evaluation is $\leq 5$ weeks.

Patients received treat-to-target-oriented treatment. Traditional disease-modifying anti-rheumatic drugs (DMARDs) were used in $99 \%$ of our population, with or without corticosteroids (20 to $40 \%$ ).

\section{Clinical evaluations}

At baseline, a complete medical history and sociodemographic characteristics were obtained. Blood samples after 9 to 12 hours fast included at least serum glucose (GLU), total cholesterol, triglycerides (TG), high-density lipoprotein-cholesterol (C-HDL), low-density lipoproteincholesterol, uric acid, erythrocyte sedimentation rate (ESR), C-reactive protein (CRP), rheumatoid factor and antibodies to cyclic citrullinated proteins (ACCP). Urine analysis was also performed. For serum GLU and lipid determinations, commercially available reagents from Beckman Co. (Limerick, Ireland) for the Synchron analyzer (Laboratorios Clínicos del Instituto Nacional de Ciencias Médicas y Nutrición Salvador Zubirán, Mexico City, Distrito Federal, México) were used. The laboratory obtained ISO 9001:2008 certification (since 30 April 2004, valid from 29 April 2013 until 28 April 2016).

Standard baseline and consecutive rheumatic evaluations included, height, weight and blood pressure measurements, extended joint counts, physician and patient-reported outcomes $[25,26]$, disease activity score evaluated in 28 joints (DAS28) [27], adverse events and comorbidity. Blood pressure was measured twice in each case in which initial measurement was $\geq 130 / 90 \mathrm{mmHg}$ unless the patient had a previous diagnosis of systemic arterial hypertension. Measurements were performed after a 5-minute resting period. Body weight and height were performed by a trained nurse, 
usually on the same equipment that was regularly calibrated according to the manufacturer's recommendations.

Patients were evaluated every 2 months during the first 2 years of follow-up, and thereafter every 2,4 or 6 months (fixed and scheduled for all patients). At fixed 6-month intervals, analysis in order to measure serum GLU, total cholesterol, TG, C-HDL, low-density lipoprotein-cholesterol, uric acid, ESR, CRP and urine analysis were scheduled. Medical evaluations were performed by the same rheumatologist and the information was recorded on standardized formats.

RA treatment records included previous treatment (defined as prescribed during the month prior to the baseline evaluation) and current treatment (at baseline and consecutive evaluations), which included names, doses, schedule, order start and stop dates of DMARDs, of corticosteroids and of nonsteroid anti-inflammatory drugs. In addition, any other drug indicated for a comorbid condition was also recorded; for the present study, names, doses, schedule, order start and stop dates of antihypertensive, antidiabetic and lipid-lowering medications were obtained. Information regarding treatment was recorded after a direct interview on a drug record registry applied at scheduled evaluations [28].

Up to March 2014, charts from 162 consecutive patients with early RA were reviewed. In order to accomplish the first objective, only RA patients with completed baseline blood pressure, weight and height, and serum TG, C-HDL and GLU levels were included (two patients were excluded); there were 160 patients left.

Of the 160 patients with complete baseline data, 19 were lost to follow-up soon after the baseline evaluation (and their baseline characteristics did not differ from those patients with follow-up) and 28 additional patients had prevalent MetS. Accordingly, there were 113 patients with at least 6 months of follow-up and MetS-free baseline, in whom incidental MetS was investigated.

Finally, to accomplish the second objective related to MetS and its impact on remission, data from patients with at least 24 months of follow-up were analyzed $(n=133)$. This lag time was chosen based on previous reports that defined median time to sustained remission in our cohort as $13.6( \pm 8.8)$ months [29].

\section{Control population}

To achieve the first objective, one control for each RA patient was randomly selected from a local database that included data from more than 10,000 Mexican Mestizo adults without either known medical condition or treatment, in whom serum samples were obtained in order to investigate the prevalence of the MetS in Central Mexico. Controls were matched according to age ( \pm 5 years), gender, smoking habit (see definition below), years of education, menopause status and urban residency.
To achieve the second objective, a case-control study nested within a cohort was designed; cases consisted of RA patients with incidental MetS and controls consisted of RA patients who never developed MetS during their follow-up. Controls were matched according to gender, age, index date (as defined when MetS was diagnosed or equivalent visit in MetS-free RA patients), menopause status, presence of rheumatoid factor or ACCP, and follow-up.

\section{Variables and definitions}

Body mass index (BMI) was calculated as weight $(\mathrm{kg}) /$ height $\left(\mathrm{m}^{2}\right)$.

Smoking status was self-reported at the baseline evaluation and categorized as never smoker, former smoker (at least one cigarette per day for at least 3 months during their lifetime but who do not currently smoke) or current smoker (at least one cigarette/day for at least 3 months).

Postmenopausal women were self-reported and defined as women $\geq 48$ years of age who have been amenorrheic for at least 2 years, or females with bilateral oophorectomy or females with documented hysterectomy aged $\geq 47$ years [30].

Fasting GLU, uric acid, total cholesterol, low-density lipoprotein-cholesterol, C-HDL and TG were measured in serum and reported in milligrams per deciliter.

Sustained remission was defined based on the DAS28 if score $\leq 2.6$ [31] and according to 2012 American College of Rheumatology/European League Against Rheumatism criteria [32] and if maintained for at least 6 months of follow-up.

Hypertension was defined if recorded on the charts, or antihypertensive medication was used, or a diastolic blood pressure $\geq 90 \mathrm{mmHg}$ was detected or a systolic blood pressure $\geq 140 \mathrm{mmHg}$ was detected.

Diabetes mellitus was defined if a physician diagnosis was recorded on the charts, if antidiabetic medication was recorded or if a fasting blood sugar level $\geq 126 \mathrm{mg} / \mathrm{dl}$ was detected.

MetS was defined according to three sets of criteria (Table 1) $[22,33,34]$. In all of these sets, BMI $\geq 30 \mathrm{~kg} / \mathrm{m}^{2}$ was considered a surrogate of waist circumference $\geq 102 \mathrm{~cm}$ in males and $\geq 88 \mathrm{~cm}$ in females.

\section{Ethics}

The study was approved by the Ethics Committee of the Instituto Nacional de Ciencias Médicas y Nutrición. Written informed consent was obtained in order to have the patient's charts reviewed and data presented in scientific forums or published.

\section{Statistical analysis}

Distribution of each variable was analyzed. Student's $t$ test and the chi-square test were used for normally distributed variables and the Mann-Whitney $U$ test for non-normally distributed variables. 
Table 1 Metabolic syndrome sets of criteria

\begin{tabular}{|c|c|c|}
\hline $\begin{array}{l}2001 \text { NCEP ATP III definition } \\
\text { (any three of five) }\end{array}$ & $\begin{array}{l}\text { AHA/NHLBI definition } \\
\text { (any three of five) }\end{array}$ & $\begin{array}{l}\text { IDF definition } \\
\text { (required }^{\mathrm{a}} \text { and any two of four criteria left) }\end{array}$ \\
\hline $\mathrm{BMI} \geq 30 \mathrm{~kg} / \mathrm{m}^{2}$ & $\mathrm{BMI} \geq 30 \mathrm{~kg} / \mathrm{m}^{2}$ & $\mathrm{BMI} \geq 30 \mathrm{~kg} / \mathrm{m}^{2}$ a \\
\hline $\mathrm{TG} \geq 150 \mathrm{mg} / \mathrm{dl}$ & $\mathrm{TG} \geq 150 \mathrm{mg} / \mathrm{dl}$ or treatment for elevated TG & $\mathrm{TG} \geq 150 \mathrm{mg} / \mathrm{dl}$ or treatment for elevated TG \\
\hline $\mathrm{C}-\mathrm{HDL}<40 \mathrm{mg} / \mathrm{dl}$ in men & $\mathrm{C}-\mathrm{HDL}<40 \mathrm{mg} / \mathrm{dl}$ in men & $\mathrm{C}-\mathrm{HDL}<40 \mathrm{mg} / \mathrm{dl}$ in men \\
\hline $\mathrm{C}-\mathrm{HDL}<50 \mathrm{mg} / \mathrm{dl}$ in women & $\mathrm{C}-\mathrm{HDL}<50 \mathrm{mg} / \mathrm{dl}$ in women & $\mathrm{C}-\mathrm{HDL}<50 \mathrm{mg} / \mathrm{dl}$ in women \\
\hline $\begin{array}{l}\text { Blood pressure } \geq 130 / 85 \mathrm{mmHg} \text { or previous } \\
\text { hypertension diagnosis }\end{array}$ & $\begin{array}{l}\text { Blood pressure } \geq 130 / 85 \mathrm{mmHg} \text { or previous } \\
\text { hypertension diagnosis }\end{array}$ & $\begin{array}{l}\text { Blood pressure } \geq 130 / 85 \mathrm{mmHg} \text { or previous } \\
\text { hypertension diagnosis }\end{array}$ \\
\hline Fasting glucose $\geq 110 \mathrm{mg} / \mathrm{dl}$ or previous type $2 \mathrm{DM}$ & Fasting glucose $\geq 100 \mathrm{mg} / \mathrm{dl}$ or previous type $2 \mathrm{DM}$ & Fasting glucose $\geq 100 \mathrm{mg} / \mathrm{dl}$ or previous type $2 \mathrm{DM}$ \\
\hline
\end{tabular}

To summarize cumulative outcomes (disease activity, disability) or variables (CRP, ESR), the mean of consecutive values from corresponding evaluations was obtained.

Follow-up missing data varied from 3\% (for BMI) to $20 \%$ (for serum GLU levels). Imputation was calculated for linear regression method, considering an arbitrary pattern of missing values.

Prevalence of MetS was determined based on different sets of criteria applied at baseline or within 2 months from baseline evaluation. The prevalence of the MetS was compared between early RA and matched controls using Fisher's exact test.

Logistic and Cox regression's models were used: to evaluate the risk of MetS (defined at the baseline evaluation); to achieve remission; to identify predictors of incidental MetS; and to investigate incidental MetS as a predictor of sustained remission. In all cases, selection of variables to be included was based on their statistical significance in the bivariate analysis; a cutoff point was established based on the number of variables $a$ priori included in order to avoid overfitting of the models; based on the number of outcomes of interest, four or five variables were included. Correlation between variables was also examined, and when significant only one variable was selected. Selection was based on variables' clinical relevance; in all cases, correlated variables were switched into the models to test the integrity of the results. Finally, if a variable was deemed to be clinical significant, its inclusion was forced into the model (cumulative treatment).

In the first model, there were no variables with statistical significance in the univariate analysis and the covariates included a priori were age, gender and MetS at baseline evaluation.

In the second analysis, variables selected were age (correlated to menopause, $r=0.5$ and to years of formal education, $r=0.3$ ), BMI, cumulative DAS28 (correlated to cumulative ESR, $r=0.75$, to cumulative CRP, $r=0.4$ and to cumulative HAQ, $r=0.67$ ) and follow-up (correlated to erosions at index date, $r=0.26), P \leq 0.001$ for all correlations.
In the third analysis, variables included were baseline DAS28 (correlated to ESR, $r=0.6$, to HAQ, $r=0.67$ and to CRP, $r=0.6$ ), incidental MetS (correlated to BMI, $r=$ 0.4 and to obesity, $r=0.3$ ), disease duration at baseline, ACCP and age $(P \leq 0.001$ for correlations); cumulative treatment was also forced into models.

All statistical tests were two-sided and evaluated at the 0.05 significance level. Statistical analysis was performed using the SPSS/PC program (v.17.0; IBM SPSS Statistics, Chicago, IL, USA).

\section{Results}

\section{Population characteristics at cohort entry}

At baseline 160 patients had complete data, as summarized in Table 2. Patients were more frequently middleaged females (142 female, mean \pm standard deviation age: $38.1 \pm 12.8$ years) and had median (range) BMI of $25.9 \mathrm{~kg} / \mathrm{m}^{2}$ (18.1 to $\left.46.8 \mathrm{~kg} / \mathrm{m}^{2}\right)$. The population had short disease duration, was most frequently rheumatoid factor-positive and ACCP-positive, and had high disease activity and moderate disability. A minority of patients had erosive disease (9.4\%). Comorbid conditions were present in 82 patients $(51.3 \%)$, among which were obesity in 35 patients $(21.9 \%)$, hypertension in 13 patients $(8.1 \%)$ and diabetes in six patients (3.8\%). Few patients were receiving DMARDs when referred to the clinic (27.5\%), although $36.9 \%$ were on oral corticosteroids.

\section{Characteristics and prevalence of metabolic syndrome in RA patients and comparison with matched healthy controls (first objective)}

In RA patients, the prevalence of MetS varied from $11.3 \%$ (according to the International Diabetes Federation definition) to $17.5 \%$ (according to the American Heart Association/National Heart, Lung and Blood Institute (AHA/NHLBI) definition). In healthy matched controls, prevalence of Mets was significantly higher and varied from 26.3\% (according to the International Diabetes Federation definition) to $30 \%$ (according to the 
Table 2 Baseline characteristics of the whole population and comparison between patients with/without metabolic syndrome (according to AHA/NHLBI definition)

\begin{tabular}{|c|c|c|c|c|c|}
\hline Characteristic & $\begin{array}{l}\text { Controls } \\
(n=160)\end{array}$ & $\begin{array}{l}\text { Whole population } \\
(n=160)\end{array}$ & $\begin{array}{l}\text { Patients with MetS } \\
(n=28)\end{array}$ & $\begin{array}{l}\text { Patients without MetS } \\
(n=132)\end{array}$ & $P$ value $^{\mathrm{a}}$ \\
\hline \multicolumn{6}{|l|}{ Socio-demographic } \\
\hline Female gender & $142(88.8)$ & $142(88.8)$ & $22(78.6)$ & $120(90.9)$ & 0.09 \\
\hline Age (years) & $38 \pm 12.4$ & $38.1 \pm 12.8$ & $43.1 \pm 10.5$ & $37 \pm 13$ & 0.02 \\
\hline Years of formal education & $10.9 \pm 3.8$ & $10.9 \pm 3.8$ & $10.8 \pm 3.5$ & $11 \pm 3.8$ & 0.87 \\
\hline Current smokers & $16(10)$ & $16(10)$ & $2(7.1)$ & $14(10.6)$ & 0.74 \\
\hline Females with menopause (142 female) & $14(9.9)$ & $14(9.9)$ & $3(13.6)$ & $11(9.2)$ & 0.46 \\
\hline $\mathrm{BMI}\left(\mathrm{kg} / \mathrm{m}^{2}\right)$ & 25.5 (19.2 to 41$)$ & 25.9 (18.1 to 46.8$)$ & 30.2 (23 to 46.8$)$ & 24.8 (18 to 41.7$)$ & 0.000 \\
\hline \multicolumn{6}{|l|}{ Disease characteristics } \\
\hline Disease duration (months) & NA & $5.3(0.47$ to 11.5$)$ & $4.3(1.4$ to 10.5$)$ & $5.3(0.5$ to 12.5$)$ & 0.13 \\
\hline Patients with RF & NA & $130(81.3)$ & $25(89.3)$ & $105(79.5)$ & 0.29 \\
\hline Patients with ACCP & NA & $134(83.8)$ & $26(92.9)$ & $108(81.8)$ & 0.26 \\
\hline DAS28 & NA & $6(2$ to 8.7$)$ & 6.1 (3 to 8.6) & $6(2$ to 8.7$)$ & 0.94 \\
\hline ESR (mm/hour) & NA & $23(2$ to 102$)$ & 22 (3 to 77 ) & 23 (2 to 102$)$ & 0.86 \\
\hline CRP (mg/dl) & NA & $0.73(0$ to 14.7$)$ & $0.76(0.1$ to 8.5$)$ & $0.73(0$ to 14.7$)$ & 0.95 \\
\hline $\mathrm{HAQ}$ & NA & $1.4(0$ to 3$)$ & $1.4(0$ to 3$)$ & $1.5(0.3)$ & 0.39 \\
\hline Patients with erosions & NA & $15(9.4)$ & $6(21.4)$ & $9(6.8)$ & 0.03 \\
\hline \multicolumn{6}{|l|}{ Comorbid conditions } \\
\hline Patients with $\geq 1$ comorbid condition & NA & $82(51.3)$ & $22(78.6)$ & $60(45.5)$ & 0.001 \\
\hline Patients with diabetes & NA & $6(3.8)$ & $5(17.9)$ & $1(0.8)$ & 0.001 \\
\hline Patients with hypertension & NA & $13(8.1)$ & $9(32.1)$ & $4(3)$ & 0.000 \\
\hline Patients with $\mathrm{BMI} \geq 30 \mathrm{~kg} / \mathrm{m}^{2}$ & NA & $35(21.9)$ & $18(75)$ & $17(12.5)$ & 0.000 \\
\hline \multicolumn{6}{|l|}{ Treatment } \\
\hline Patients with DMARDs & NA & $44(27.5)$ & $9(32.1)$ & $35(26.5)$ & 0.64 \\
\hline Patients with corticosteroids & NA & $59(36.9)$ & $11(39.3)$ & $48(36.4)$ & 0.83 \\
\hline Patients with antimalarials & NA & $26(16.3)$ & $5(17.9)$ & $21(15.9)$ & 0.78 \\
\hline Patients with other drugs & NA & $83(51.9)$ & $14(50)$ & $69(52.3)$ & 0.84 \\
\hline
\end{tabular}

Data presented as $n$ (\%), mean \pm standard deviation or median (range). ACCP, antibodies to cyclic citrullinated peptides; AHA/NHLBI, American Heart Association/ National Heart, Lung and Blood Institute; BMI, body mass index; CRP, C-reactive protein; DAS28, disease activity score evaluated in 28 joints; DMARD, diseasemodifying anti-rheumatic drug; ESR, erythrocyte sedimentation rate; HAQ, Health Assessment Questionnaire; MetS, metabolic syndrome; NA, not applicable; $\mathrm{RF}$, rheumatoid factor. ${ }^{\mathrm{a} C o m p a r i s o n}$ between rheumatoid arthritis patients with/without MetS.

AHA/NHLBI definition), as shown in Figure $1(P \leq 0.01$ for all comparisons).

Distribution of individual components of the MetS in RA patients and controls was as follows: BMI $\geq 30 \mathrm{~kg} / \mathrm{m}^{2}$ ranged from 64.3 to $100 \%$, TG $\geq 150 \mathrm{mg} / \mathrm{dl}$ from 92.9 to $95.8 \%$, C-HDL $<40 \mathrm{mg} / \mathrm{dl}$ (men) or $<50 \mathrm{mg} / \mathrm{dl}$ (women) from 94.4 to $96.4 \%$, blood pressure $\geq 130 / 85 \mathrm{mmHg}$ (or previous hypertension diagnosis) from 20.8 to $22.2 \%$, and fasting GLU $\geq 100 \mathrm{mg} / \mathrm{dl}$ (or previous type 2 diabetes mellitus) from 27.8 to $53.6 \%$. Comparison of individual components between RA patients and healthy controls showed that the former less frequently had the BMI component and tend to more frequently have the GLU component, as shown in Table 3.

Comparison of baseline characteristics between patients with/without prevalent MetS is summarized in
Table 2. Patients with MetS according to AHA/NHLBI definition were older, had greater BMI, had more erosive disease and tended to be more frequently men than their counterparts. As expected, patients with MetS had also more diabetes, hypertension and obesity, while other comorbid conditions were equally represented. Variables related to disease activity and treatment were similar in both groups. Similar results were obtained when the 2001 National Cholesterol Education Program Adult Treatment Panel III definition and the International Diabetes Federation definition were applied (data not shown).

\section{Metabolic syndrome and the probability for achieving} remission status (second objective)

As already mentioned, 133 patients had at least 24 months of follow-up, of whom 108 (81\%) had at least $\geq 1$ sustained 


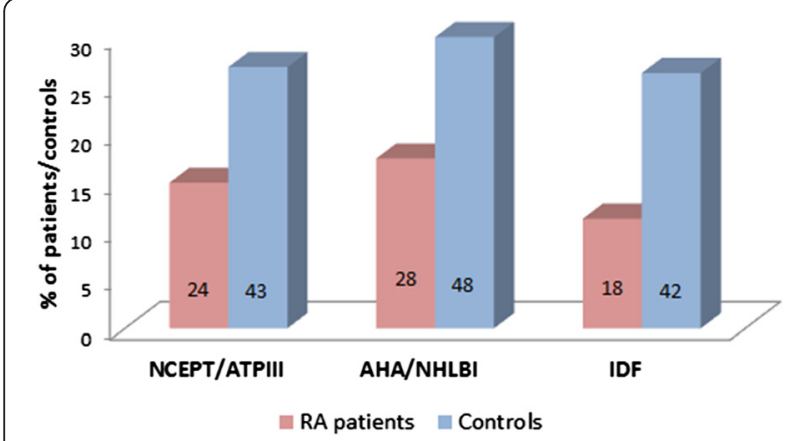

Figure 1 Comparison of prevalence of metabolic syndrome between rheumatoid arthritis patients and matched controls. Numbers inside bars represent the number of patients and controls with metabolic syndrome according to the three different definitions. AHA/NHLBI, American Heart Association/National Heart, Lung and Blood Institute; IDF, International Diabetes Federation; NCEPT/ATPIII, National Cholesterol Education Program Adult Treatment Panel III; RA, rheumatoid arthritis.

American College of Rheumatology/European League Against Rheumatism remission state. They achieved remission at (median, range) 14 months (4 to 80 months) of follow-up and remained in remission for 16 months (6 to 104 months). Twenty-two out the 108 patients who achieved remission (20.4\%) had MetS according to AHA/ NHLBI criteria and no differences were seen in the percentage of patients achieving remission, time to remission state and time on sustained remission between patients with/without MetS. Cox regression analysis did not identify MetS as a risk factor for any construct related to remission (data not shown). Similar results were obtained when remission was defined according to DAS28 (data not shown).

Table 3 Comparison of the distribution of individual components of metabolic syndrome (according to AHA/ NHLBI definition) between RA patients and controls

\begin{tabular}{lllc}
\hline & $\begin{array}{l}\text { Early RA } \\
\text { patients } \\
(\boldsymbol{n}=\mathbf{1 6 0})\end{array}$ & $\begin{array}{l}\text { Controls } \\
(\boldsymbol{n}=160)\end{array}$ & P value \\
\hline $\begin{array}{l}\text { Patients who met AHA/NHLBI MetS } \\
\text { definition }\end{array}$ & $28(17.5)$ & $48(30)$ & 0.01 \\
$\begin{array}{l}\text { Patients within each category of MetS } \\
\text { definition with a particular individual }\end{array}$ & & & \\
component & $18(64.3)$ & $42(87.5)$ & 0.02 \\
BMI component & $26(92.9)$ & $43(89.6)$ & 1 \\
$\begin{array}{l}\text { TG component } \\
\text { C-HDL component }\end{array}$ & $27(96.4)$ & $46(95.8)$ & 1 \\
Blood pressure component & $10(35.7)$ & $11(22.9)$ & 0.29 \\
Fasting glucose component & $15(53.6)$ & $16(33.3)$ & 0.10
\end{tabular}

Data presented as $n$ (\%). AHA/NHLBI, The American Heart Association/National Heart, Lung and Blood Institute; BMI, body mass index; C-HDL, high-density lipoprotein-cholesterol; MetS, metabolic syndrome; RA, rheumatoid arthritis; TG, triglycerides.
Incidental metabolic syndrome in RA patients and impacts on major outcomes (second objective)

To explore the relationship between MetS and disease activity-related outcomes we first identified RA patients who developed incidental MetS at some point during their follow-up. According to the AHA/NHLBI definition, 39 patients (34.5\%) out of 113 baseline MetS-free patients with adequate follow-up developed incidental MetS. The global MetS incidence rate was 8 per 100 persons/year; as shown in Figure 2, the annual incidental rate of MetS tended to decrease after the third year of follow-up.

Baseline characteristics and cumulative disease characteristics up to the index date (when incident MetS was identified/or up to last follow-up) were then compared between RA patients with/without incidental Mets. Results are summarized in Table 4 and showed that RA patients who developed incidental MetS were older, were less educated, were more frequently postmenopausal, had higher BMI, had more cumulative disease activity and disability, had previous incidental MetS diagnosis, developed erosive disease more frequently than their counterparts and had longer follow-up. In order to identify predictors of MetS, different Cox regression models were tested in which baseline demographic and anthropometric variables were included in addition to cumulative variables related to disease activity. Table 5 presents the different models tested; in all of the models, cumulative DAS28 and baseline BMI were the only predictors for incidental MetS. When RA-related treatment was forced into the model, similar results were obtained.

We then explored the impact of MetS on disease activity. A case-control study nested within a cohort was designed; among the 39 RA patients with incidental MetS, 30 were paired to 30 corresponding matched controls (age, gender, index date, menopause status, RF, ACCP and follow-up). Cumulative outcomes related to disease

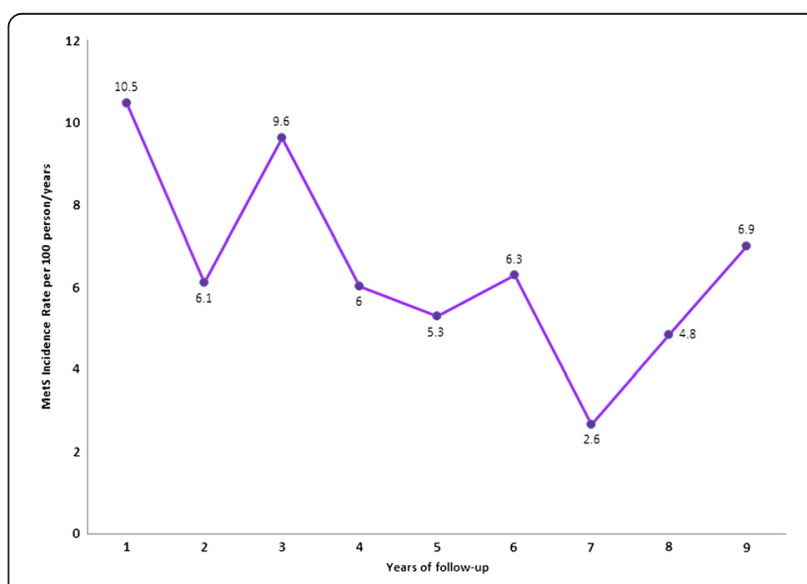

Figure 2 Annual metabolic syndrome incidence rate. MetS, metabolic syndrome. 
Table 4 Comparison of rheumatoid arthritis patient characteristics between patients with/without incidental metabolic syndrome

\begin{tabular}{|c|c|c|c|}
\hline Characteristics & $\begin{array}{l}\text { MetS-free } \\
\text { patients } \\
(n=74)\end{array}$ & $\begin{array}{l}\text { Patients with } \\
\text { incidental MetS } \\
(n=39)\end{array}$ & $P$ value \\
\hline \multicolumn{4}{|l|}{ Socio-demographic } \\
\hline Female gender & $68(91.9)$ & $35(89.7)$ & 0.74 \\
\hline Age (years) & $33.6 \pm 11.9$ & $42.7 \pm 13.8$ & 0.000 \\
\hline Years of formal education & $11.6 \pm 3.6$ & $10 \pm 4.2$ & 0.04 \\
\hline Current smokers & $10(13.5)$ & $2(5.1)$ & 0.21 \\
\hline $\begin{array}{l}\text { Females with menopause } \\
\text { (142 female) }\end{array}$ & $4(4.4)$ & $7(20)$ & 0.03 \\
\hline BMI $\left(\mathrm{kg} / \mathrm{m}^{2}\right)$ & 23.9 (21.5 to 26.6) & 26.8 (24.5 to 29.8$)$ & 0.000 \\
\hline \multicolumn{4}{|l|}{ Disease characteristics } \\
\hline $\begin{array}{l}\text { Disease duration } \\
\text { (months) }\end{array}$ & 5.4 (3.9 to 7) & $5.3(2.9$ to 7.3$)$ & 0.38 \\
\hline Patients with RF & $59(79.7)$ & $29(74.4)$ & 0.63 \\
\hline Patients with ACCP & $63(85.1)$ & $29(74.4)$ & 0.21 \\
\hline Cumulative $^{a}$ DAS28 & $2.4(2.1$ to 3.05$)$ & $3.3(2.7$ to 5.8$)$ & 0.000 \\
\hline $\begin{array}{l}\text { Cumulative }{ }^{a} \text { ESR } \\
\text { (mm/hour) }\end{array}$ & 12.5 (8.6 to 18.2$)$ & $21(10.2$ to 35$)$ & 0.008 \\
\hline Cumulative $^{a}$ CRP (mg/dl) & 0.28 (0.15 to 0.58$)$ & $0.52(0.26$ to 1.21$)$ & 0.007 \\
\hline Cumulative $^{a} \mathrm{HAQ}$ & $0.2(0.12$ to 0.43$)$ & 0.38 (0.25 to 1.13$)$ & 0.001 \\
\hline $\begin{array}{l}\text { Patients with erosions at } \\
\text { index date }{ }^{a}\end{array}$ & $27(34.5)$ & $23(59)$ & 0.03 \\
\hline Follow-up (months) & 72 (42 to 94.5) & 90 (70 to 108$)$ & 0.003 \\
\hline \multicolumn{4}{|l|}{ Comorbid conditions } \\
\hline $\begin{array}{l}\text { Patients with } \geq 1 \\
\text { comorbid condition }\end{array}$ & $35(47.3)$ & $20(51.3)$ & 0.67 \\
\hline Patients with diabetes & 0 & $1(2.6)$ & 0.35 \\
\hline Patients with hypertension & $1(1.4)$ & $3(7.7)$ & 0.12 \\
\hline $\begin{array}{l}\text { Patients with } \\
\mathrm{BMI} \geq 30 \mathrm{~kg} / \mathrm{m}^{2}\end{array}$ & $3(4.1)$ & $10(25.6)$ & 0.001 \\
\hline \multicolumn{4}{|l|}{ Treatment at baseline } \\
\hline Patients with DMARDs & $15(32.6)$ & $15(38.5)$ & 0.12 \\
\hline $\begin{array}{l}\text { Patients with } \\
\text { corticosteroids }\end{array}$ & $26(35.1)$ & $12(30.8)$ & 0.68 \\
\hline $\begin{array}{l}\text { Patients with } \\
\text { antimalarials }\end{array}$ & $12(16.2)$ & $8(20.5)$ & 0.61 \\
\hline Patients with other drugs & $37(50)$ & $22(56.4)$ & 0.56 \\
\hline
\end{tabular}

Data presented as $n$ (\%), mean \pm standard deviation or median (range). ACCP, antibodies to cyclic citrullinated peptides; BMI, body mass index; CRP,

C-reactive protein; DAS28, disease activity score evaluated in 28 joints; DMARD, disease-modifying anti-rheumatic drug; ESR, erythrocyte sedimentation rate; $H A Q$, Health Assessment Questionnaire; MetS, metabolic syndrome; RF, rheumatoid factor. ${ }^{a}$ Considered up to MetS diagnosis in patients with incidental MetS and up to last follow-up in the patients without incidental MetS.

activity were compared between RA cases and controls after the index date and results are summarized in Figure 3A,B. RA patients with incidental MetS had higher median (range) cumulative DAS28 after the index date than RA patients who never developed MetS over
Table 5 Cox regression models to define predictors for incidental metabolic syndrome (according to AHA/NHLBI definition)

\begin{tabular}{llll}
\hline & Model 1 & Model 2 & Model 3 \\
\hline Age & $1.005,0.98$ to 1.03 & $1.009,0.98$ to 1.04 & $0.99,0.98$ to 1.02 \\
BMI & $1.14,1.04$ to 1.26 & & $1.14,1.04$ to 1.25 \\
BMI $\geq 25 \mathrm{~kg} / \mathrm{m}^{2}$ & & $3.07,1.7$ to 9.26 & \\
Cumulative & $1.79,1.33$ to 2.43 & $1.92,1.41$ to 2.62 & $1.91,1.37$ to 2.68 \\
DAS28 & & & $0.71,0.32$ to 1.6 \\
Erosions at & & & \\
index date & & & \\
Follow-up & $0.99,0.97$ to 1.004 & $0.99,0.98$ to 1.01 & \\
\hline
\end{tabular}

Data presented as Exp ( $\beta$ ), 95\% confidence interval. AHA/NHLBI, American Heart Association/National Heart, Lung and Blood Institute; BMI, body mass index; DAS28, disease activity score evaluated in 28 joints.

follow-up (Figure 3A); also, less RA patients from the former group achieved or maintained remission while more patients had disease flare or never achieved remission when compared with the control group (Figure 3B). We then compared characteristics from patients who achieved or maintain remission after the index date $(n=$ $46)$ and those who never achieved remission $(n=14)$; as shown in Table 6, the former had lower BMI, longer disease duration at baseline evaluation, lower baseline disease activity (as per DAS28, ESR and CRP) and disability, developed incidental MetS less frequently and were more frequently obese at the baseline evaluation. Baseline (not shown) and cumulative treatment before sustained remission was similar (corticosteroid use and number of DMARDs/patient). Finally, logistic regression analysis was performed in order to identify predictors for remission after incident MetS. Table 7 presents the different models tested; in all of them, incidental MetS and baseline DAS28 were the only predictors for achieving or maintaining a sustained remission status.

\section{Discussion}

In the present study we found that 11 to $18 \%$ of Mexican Mestizo early RA patients had MetS diagnosed as a comorbid condition and this figure was lower for prevalence of MetS in healthy controls. Distribution of the TG and CHDL components of MetS was similar between patients and controls, but early RA patients presented less frequently the BMI component while the controls showed a similar tendency for the GLU and hypertension components. Patients with prevalent MetS were older, had greater BMI, had more radiographic damage and more frequently had comorbid conditions related to MetS than RA patients without the syndrome.

In 2008, Chung and colleagues were the first to demonstrate that prevalence of MetS in patients with RA was increased when compared with matched controls [15]. 


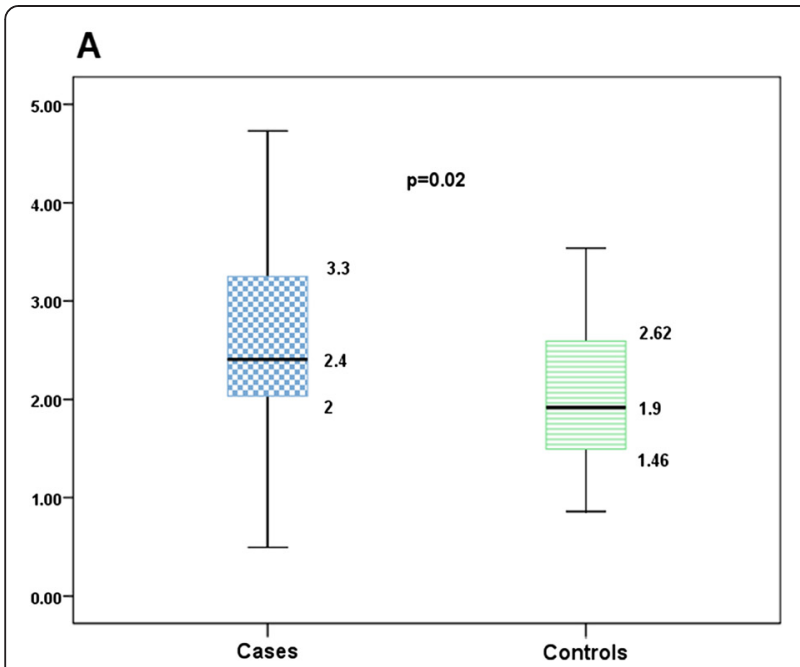

B

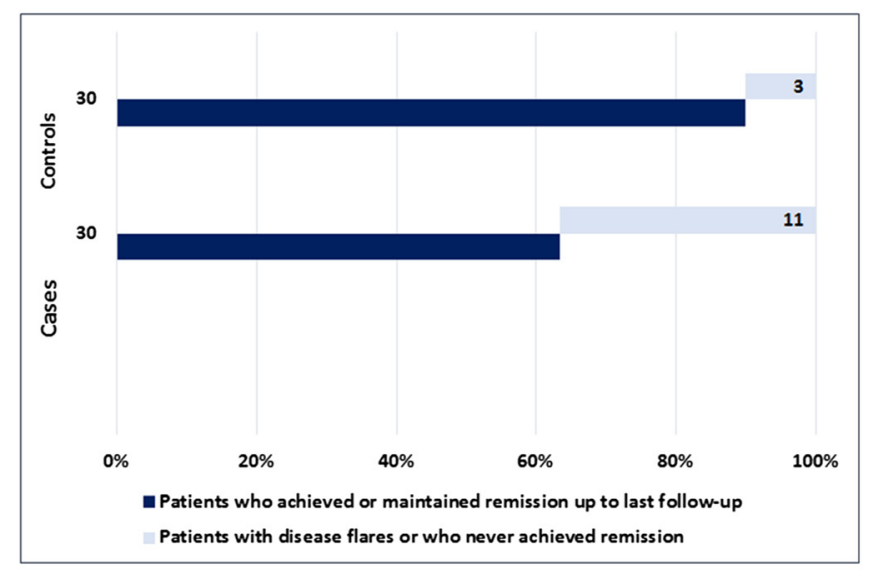

Figure 3 Comparison of disease activity-related outcomes after the index date between cases and controls. Comparison of disease activity-related outcomes after the index date, between rheumatoid arthritis (RA) patients with incidental metabolic syndrome (Mets; cases) and their matched controls (RA patients who did not develop incidental MetS up to last follow-up). (A) Median (range) cumulative disease activity score evaluated in 28 joints after the index date in RA patients who developed incidental MetS and their controls. (B) Distribution ( $n$ (\%)) of patients and controls who achieved or maintained remission and of patients and controls with disease flare or who never achieved remission, from the index date up to last follow-up.

Patients with long-standing disease had the greatest prevalence. A recent meta-analysis by Zhang and colleagues has proven further evidence in support of a higher prevalence of MetS in RA patients, with an overall odds ratio of 1.24 (95\% confidence interval, 1.03 to 1.50 ), although geographic area and the criteria used influenced the association [14]; interestingly, none of the 12 studies included in the meta-analysis was performed in Mexican patients. Conflicting results regarding this topic were highlighted in two excellent reviews by da Cunha and colleagues in 2011 [35] and Ferraz-Amaro and colleagues in 2013 [36]; both studies concluded that MetS is not uncommon in patients with RA but mentioned published exceptions with regard to a greater prevalence in RA patients [18,37-40]. More recently, Mok and colleagues estimated a prevalence of $20 \%$ in 699 Chinese patients, of whom 209 had disease duration of less than 2 years [41]. In most of the studies reported (including exceptions), matching of controls has been restricted to age and sex, and sometimes to race. We performed a more precise matching, including characteristics that do affect the prevalence of MetS in Mexican Mestizo patients such as years of education [20], in addition to age, gender, smoking habit, menopause status and urban residency. This unique characteristic to our study, along with a population with short disease duration and younger age at diagnosis (mean age 38.1 years), may explain our prevalence figure of MetS in RA patients in the lower range (up to $18 \%$ ), which in fact is similar to that reported by Zonana-Nacach and colleagues in the only study performed in Mexican patients [42]. Also, our prevalence figure of MetS in matched controls, which may be considered high, is similar to that reported in the National Health and Nutrition Survey in 2006 [20], when analyzed by age group.

We found among the individual components of MetS that differences between patients and controls were observed for the BMI component, which was more frequent in controls; meanwhile, opposite tendencies were seen for the hypertension and GLU components, partially consistent with studies performed in early RA $[15,16]$. More than one-half of our active RA patients with MetS presented the GLU component; this figure may be explained by a negative correlation of high-grade inflammation with circulating adiponectin concentrations as proposed by González-Gay and colleagues; their study involved patients with severe RA in whom (low) adiponectin concentrations further correlated with high plasma GLU [43]. Ultimately, discrepancies with other studies may be explained by the particular distribution of individual components of the MetS in our population along with distinctive epidemiological, clinical and serological characteristics of Mexican patients with RA.

Our early arthritis cohort of Mexican Mestizo patients has particular characteristics [24,28,29] that were considered for the second aim of the study and confer relevance to findings, such as a homogeneous population of patients with early disease and substantial comorbidity (real-life patients), standardized and complete follow-up by the same rheumatologist in a real clinical setting, periodic evaluation of comorbidity, treatment and physician-reported and patient-reported outcomes, use of conventional DMARDs according to a treat-to-target 
Table 6 Comparison of characteristics between RA patients who never achieved remission and those who achieved and maintained remission (case-control study, nested within the cohort)

\begin{tabular}{|c|c|c|c|}
\hline Characteristic & $\begin{array}{l}\text { RA patients who } \\
\text { achieved and } \\
\text { maintained } \\
\text { remission } \\
(n=46)\end{array}$ & $\begin{array}{l}\text { RA patients who } \\
\text { never achieved } \\
\text { sustained } \\
\text { remission } \\
(n=14)\end{array}$ & $P$ value \\
\hline \multicolumn{4}{|l|}{ Socio-demographic } \\
\hline Female gender & 40 (87\%) & $14(100)$ & 0.32 \\
\hline Age (years) & $38.2 \pm 10.5$ & $38.7 \pm 12.5$ & 0.88 \\
\hline $\begin{array}{l}\text { Years of formal } \\
\text { education }\end{array}$ & $10.5 \pm 8.8$ & $10 \pm 7.7$ & 0.43 \\
\hline Current smokers & $5(10.9)$ & $0(0)$ & 0.33 \\
\hline $\begin{array}{l}\text { Females with } \\
\text { menopause } \\
\text { (142 female) }\end{array}$ & $2(5)$ & $1(7)$ & 1 \\
\hline Baseline BMI $\left(\mathrm{kg} / \mathrm{m}^{2}\right)$ & 25.1 (22 to 27.5 ) & 27.8 (23.1 to 30.4$)$ & 0.05 \\
\hline \multicolumn{4}{|l|}{$\begin{array}{l}\text { Disease } \\
\text { characteristics }\end{array}$} \\
\hline $\begin{array}{l}\text { Disease duration } \\
\text { (months) }\end{array}$ & $5.8(4.1$ to 7.7$)$ & 3.3 (1.6 to 6 ) & 0.03 \\
\hline Patients with ACCP & 38 (82.6) & $13(92.9)$ & 0.67 \\
\hline Baseline DAS28 & 6 (4.6 to 6.8$)$ & 7.3 (6.5 to 7.8$)$ & 0.002 \\
\hline Baseline ESR (mm/hour) & 24.5 (14.3 to 37$)$ & 43 (28.3 to 59.5) & 0.012 \\
\hline Baseline CRP (mg/dl) & 1 (0.3 to 3.4) & $2.4(1.4$ to 6.1$)$ & 0.05 \\
\hline Baseline HAQ & 1.4 (0.6 to 2) & 2.3 (1.6 to 3 ) & 0.008 \\
\hline $\begin{array}{l}\text { Patients with erosions } \\
\text { at baseline }\end{array}$ & $5(11)$ & $0(0)$ & 0.33 \\
\hline Follow-up (months) & 88 (58.5 to 108$)$ & 87 (57 to 108) & 0.96 \\
\hline Incidental MetS & 19 (41.3) & 11 (78.6) & 0.03 \\
\hline \multicolumn{4}{|l|}{ Comorbid conditions } \\
\hline Patients with diabetes & $1(2.2)$ & $0(0)$ & 1 \\
\hline $\begin{array}{l}\text { Patients with } \\
\text { hypertension }\end{array}$ & $1(2.2)$ & $0(0)$ & 1 \\
\hline $\begin{array}{l}\text { Patients with } \\
\text { BMI } \geq 30 \mathrm{~kg} / \mathrm{m}^{2}\end{array}$ & $4(8.7)$ & $6(42.9)$ & 0.007 \\
\hline \multicolumn{4}{|l|}{$\begin{array}{l}\text { Treatment up to } \\
\text { sustained remission }^{\text {a }}\end{array}$} \\
\hline $\begin{array}{l}\text { Number of } \\
\text { DMARDs/patient }\end{array}$ & 2 (2 to 2.5$)$ & 2.5 (2 to 2.75$)$ & 0.08 \\
\hline $\begin{array}{l}\text { Patients with } \\
\text { corticosteroids }\end{array}$ & $30(65.2)$ & $9(64.3)$ & 1 \\
\hline
\end{tabular}

Data presented as $n(\%)$, mean \pm standard deviation or median (range). ACCP, antibodies to cyclic citrullinated peptides; BMI, body mass index; CRP, Creactive protein; DAS28, disease activity score evaluated in 28 joints; DMARD, disease-modifying anti-rheumatic drug; ESR, erythrocyte sedimentation rate; $\mathrm{HAQ}$, Health Assessment Questionnaire; MetS, metabolic syndrome; RA, rheumatoid arthritis. ${ }^{a}$ In those who never achieved remission, complete follow-up was considered.

strategy, and substantial follow-up. To our knowledge, this is the only study in which incident MetS is determined so cause-effect inferences on the relationship between MetS and disease activity were possible. We first
Table 7 Regression models to define predictors for sustained remission

\begin{tabular}{llll}
\hline & $\begin{array}{l}\text { Model 1 } \\
\text { (parsimonious) }\end{array}$ & Model 2 & Model 3 \\
\hline DAS28 at baseline & $0.44,023$ to 0.85 & $0.50,0.21$ to 0.85 & $0.42,0.21$ to 0.85 \\
Incidental MetS & $0.23,0.05$ to 1.00 & $0.18,0.04$ to 0.89 & $0.23,0.05$ to 1.09 \\
$\begin{array}{l}\text { Disease duration } \\
\text { at baseline }\end{array}$ & $1.28,0.94$ to 1.74 & $1.26,0.93$ to 1.70 \\
ACCP & $0.20,0.02$ to 2.29 & \\
Age & & $0.97,0.90$ to 1.04 \\
\hline
\end{tabular}

Data presented as $\operatorname{Exp}(\beta), 95 \%$ confidence interval. ACCP, antibodies to cyclic citrullinated peptides; DAS28, disease activity score evaluated in 28 joints; MetS, metabolic syndrome.

described the MetS incidence rate as 8 per 100 persons/ year and showed that the annual MetS incidence rate decreased after the third year; this can be explained by a greater burden of disease activity at RA diagnosis and/or by a more intensive search of comorbid conditions in patients first attending a clinic. To our knowledge there is no information available in the literature that may help us to contrast these data.

We could not find a relation between prevalent MetS and the different outcomes related to remission (as time to remission and time on sustained remission). Similar to results described in some studies, prevalent MetS was not associated with disease activity parameters [37,38] but with erosive disease, although the latter is generally linked to a greater disease activity burden. Nonetheless, the most relevant findings were that incidental MetS and baseline disease activity were predictors for achieving and maintaining a remission status. Also, looking at the problem from the other side of the coin, cumulative disease activity and BMI were both predictors of incidental MetS. Although there are published studies that have established an association between MetS and disease-related outcomes [14,16-19,37,38,44-47], data based on a prospective design that allows risk evaluations are very limited. Gremese and Ferraccioli in their review described unpublished data from 115 longstanding RA patients with disease activity and starting anti-TNF; RA patients carrying MetS had lower chance to achieve a good response [48]. Our data support that MetS has an inflammatory milieu favoring the occurrence of RA or leading to a more severe disease. On the contrary, MetS contributes to a poorer response to therapy in RA patients, probably due to the additive effect of its low-grade inflammation to the great inflammatory burden of RA. The most relevant point from these observations may be related to the complex relationship of the different pathways, cytokines and adipocyte-derived mediators driving inflammation in RA patients with MetS; as an example, proinflammatory cytokines such as 
tumor necrosis factor alpha are involved in the pathogenesis of insulin resistance while resistin (an adipocytederived mediator) also plays an important role in the inflammatory cascade and undergoes a dramatic reduction after anti-tumor necrosis factor alpha therapy [49]. In fact, the benefits of tumor necrosis factor alpha blockade in RA patients go far beyond the local (synovial) inflammatory process, and extend to other biological actions such as improvement of endothelial dysfunction and of insulin resistance [50].

Limitations of the study include the number of patients studied, especially men. In addition, up to $50 \%$ of the patients had received corticosteroids, chloroquine and/or methotrexate 1 month before entering the cohort, and these drugs are known to affect the lipid profile and eventually alter the true prevalence of MetS [46,51]. Our clinic is established in a tertiary care center, and there is a possibility of patient selection bias; patients with mild RA may especially be underrepresented. Also, our cohort of patients with early disease is limited to a population of Mexican Mestizos who have particular genetic background, socio-demographic characteristics, treatment availability and health system referral - all of these factors potentially affect both the disease itself and MetS; accordingly, our results may not be generalized. Owing to the limited years of follow-up of our cohort, the impact of MetS on CV outcomes was not assessed, and neither was the impact of individual components of MetS, which have been shown to perform better (than currently recommended MetS definitions) in identifying subclinical atherosclerosis in RA patients [52]. A limited number of comorbid conditions were assessed in our study (obesity, hypertension and diabetes) while others such as hyperuricemia and hypothyroidism that are recognized to be independent $\mathrm{CV}$ risk factors in the general population and in RA patients were not [53]. Finally, during 10-year follow-up there were up to $20 \%$ missing data and an imputation methodology was used.

\section{Conclusions}

Mexican Mestizo RA patients referred to a tertiary care center had a prevalence of MetS variable upon the criteria applied, from 11 to $18 \%$, but lower than matched, apparently healthy controls. Up to 9 years of follow-up, the MetS incidence rate was $34.5 \%$ and the annual MetS incidence rate decreased after the third year. Disease activity and MetS had a complex association favoring a vicious circle: greater cumulative disease activity and BMI were both predictors of incidental MetS, while incidental Mets and higher disease activity at baseline predicted worse outcomes. In such a clinical context, it appears that both MetS and disease activity need to be treated and effectively controlled in order to impact disease outcomes. Ultimately, CV risk will be also impacted.

\section{Abbreviations}

ACCP: antibodies to cyclic citrullinated peptides; AHANNHLBI: American Heart Association/National Heart, Lung and Blood Institute; BMl: body mass index; C-HDL: high-density lipoprotein-cholesterol; CRP: C-reactive protein;

CV: cardiovascular; DAS28: disease activity score evaluated in 28 joints; DMARD: disease-modifying anti-rheumatic drug; ESR: erythrocyte sedimentation rate; GLU: glucose; MetS: metabolic syndrome; RA: rheumatoid arthritis; TG: triglycerides.

\section{Competing interests}

The authors declare that they have no competing interests.

\section{Authors' contributions}

FP-S participated in the conception and design of the study and reviewed the manuscript. IC-Y participated in the conception and design of the study, performed the statistical analysis and revised the manuscript, and is in charge of database integrity for the early arthritis clinic. DE-L participated in the conception and design of the study and reviewed the manuscript. CAA-S participated in the conception and design of the study and reviewed the manuscript. VP-R participated in the conception and design of the study, performed the statistical analysis and drafted the manuscript, and is in charge of the early arthritis clinic and performed the patients' clinical evaluations. All authors read and approved the final manuscript.

\section{Author's information}

FP-S is a trainee in Internal Medicine; he was assigned to the Immunology and Rheumatology Department for several months as part of his formal training process

\section{Author details}

${ }^{1}$ Department of Rheumatology and Immunology, Instituto Nacional de Ciencias Médicas y Nutrición Salvador Zubirán, Vasco de Quiroga 15, colonia sección XVI, Tlalpan 14000, México, DF, México. ²Department of Metabolism and Endocrinology, Instituto Nacional de Ciencias Médicas y Nutrición Salvador Zubirán, Vasco de Quiroga 15, colonia sección XVI, Tlalpan 14000, México, DF, México.

Received: 22 July 2014 Accepted: 3 February 2015

Published online: 20 February 2015

\section{References}

1. Solomon DH, Curhan GC, Rimm EB, Cannuscio CC, Karlson EW. Cardiovascular risk factors in women with and without rheumatoid arthritis. Arthritis Rheum. 2004:50:3444-9.

2. Wolfe F, Mitchell DM, Sibley JT, Fries JF, Bloch DA, Williams CA, et al. The mortality of rheumatoid arthritis. Arthritis Rheum. 1994;37:481-94.

3. Wallberg-Jonsson S, Ohman ML, Dahlqvist SR. Cardiovascular morbidity and mortality in patients with seropositive rheumatoid arthritis in northern Sweden. J Rheumatol. 1997;34:445-51.

4. Rodríguez-Rodríguez L, González-Juanatey C, Palomino-Morales R, VázquezRodríguez TR, Miranda-Filloy JA, Fernández-Gutiérrez B, et al. TNFA-308 (rs1800629) polymorphism is associated with a higher risk of cardiovascular disease in patients with rheumatoid arthritis. Atherosclerosis. 2011;216:125-30

5. Gonzalez-Gay MA, Gonzalez-Juanatey C, Lopez-Diaz MJ, Piñeiro A, Garcia-Porrua C, Miranda-Filloy JA, et al. HLA-DRB1 and persistent chronic inflammation contribute to cardiovascular events and cardiovascular mortality in patients with rheumatoid arthritis. Arthritis Rheum. 2007:57:125-32.

6. Hahn BH, Grossman J, Chen W, McMahon M. The pathogenesis of atherosclerosis in autoimmune rheumatic diseases: roles of inflammation and dyslipidemia. J Autoimm. 2007;28:69-75.

7. Wolfe F, Michaud K. The risk of myocardial infarction and pharmacologic and nonpharmacologic myocardial infarction predictors in rheumatoid arthritis: a cohort and nested case-control analysis. Arthritis Rheum. 2008;58:2612-21.

8. Erb N, Pace AV, Douglas KM, Banks MJ, Kitas GD. Risk assessment for coronary heart disease in rheumatoid arthritis and osteoarthritis. Scand J Rheumatol. 2004:33:293-9.

9. Escalante A, Haas RW, del Rincón I. Paradoxical effect of body mass index on survival in rheumatoid arthritis: role of comorbidity and systemic inflammation. Arch Intern Med. 2005;165:1624-9.

10. Gabriel SE. Heart disease and rheumatoid arthritis: understanding the risks. Ann Rheum Dis. 2010;69:1624-9. 
11. Gonzalez A, Maradit Kremers H, Crowson CS, Ballman KV, Roger VL, Jacobsen SJ, et al. Do cardiovascular risk factors confer the same risk for cardiovascular outcomes in rheumatoid arthritis patients as in non-rheumatoid arthritis patients? Ann Rheum Dis. 2008;67:64-9.

12. Lakka HM, Laaksonen DE, Lakka TA, Niskanen LK, Kumpusalo E, Tuomilehto J, et al. The metabolic syndrome and total and cardiovascular disease mortality in middle-aged men. JAMA. 2002;288:2709-16.

13. Reilly MP, Rader DJ. The metabolic syndrome: more than the sum of its parts? Circulation. 2003;108:1546-51.

14. Zhang J, Fu L, Shi J, Chen X, Li Y, Ma B, et al. The risk of metabolic syndrome in patients with rheumatoid arthritis: a meta-analysis of observational studies. Plos One. 2013;8:e78151.

15. Chung CP, Oeser A, Solus JF, Avalos I, Gebretsadik T, Shuintani A, et al. Prevalence of the metabolic syndrome is increased in rheumatoid arthritis and is associated with coronary atherosclerosis. Atherosclerosis. 2008;196:756-8.

16. Dao HH, Do QT, Sakamoto J. Increased frequency of metabolic syndrome among Vietnamese women with early rheumatoid arthritis: a cross-sectional study. Arthritis Res Ther. 2010;12:R218.

17. Karakoc M, Batmaz I, Sariyildiz MA, Tahtasiz M, Cevik R, Tekbas E, et al. The relationship of metabolic syndrome with disease activity and the functional status in patients with rheumatoid arthritis. J Clin Med Res. 2012;4:279-85.

18. Karvounaris SA, Sidiropoulos PI, Papadakis JA, Spanakis EK, Bertsias GK, Kritikos HD, et al. Metabolic syndrome is common among middle to older aged Mediterranean patients with rheumatoid arthritis and correlates with disease activity: a retrospective, cross-sectional, controlled study. Ann Rheum Dis. 2007;66:28-33.

19. Provan SA, Semb AG, Hisdal J, Stranden E, Agewall S, Dagfinrud H, et al. Remission is the goal for cardiovascular risk management in patients with rheumatoid arthritis: a cross-sectional comparative study. Ann Rheum Dis. 2011;70:812-7

20. Rojas R, Aguilar-Salinas CA, Jiménez-Corona A, Shamah-Levy T, Rauda J, Avila-Burgos L, et al. Metabolic syndrome in Mexican adults: results from the National Health and Nutrition Survey 2006. Salud Publica Mex. 2010;52:S11-8.

21. Schargrodsky H, Hernández-Hernández R, Champagne BM, Silva H, Vinueza $R$, Silva Ayçaguer LC, et al. CARMELA: assessment of cardiovascular risk in seven Latin-American cities. Am J Med. 2008;121:58-65.

22. Grundy SM, Cleeman JI, Daniels SR, Donato KA, Eckel RH, Franklin BA, et al. Diagnosis and management of the metabolic syndrome: an American Heart Association/National Heart, Lung, and Blood Institute Scientific Statement. Circulation. 2005;112:2735-52

23. Mody GM, Cardiel MH. Challenges in the management of rheumatoid arthritis in developing countries. Best Pract Res Clin Rheumatol. 2008;22:621-41.

24. Pascual-Ramos V, Contreras-Yáñez I, Villa AR, Cabiedes J, Rull-Gabayet M. Medication persistence over 2 years of follow-up in a cohort of early rheumatoid arhtitis patients: associated factors and relationship with disease activity and disability. Arthritis Res Ther. 2009;11:R26.

25. Ramey DR, Raynauld JP, Fries JF. The health assessment questionnaire 1992: status and review. Arthritis Care Res. 1992:5:119-29.

26. Kosinski M, Keller SD, Ware Jr JE, Hatoum HT, Kong SX. The SF-36 Health Survey as a generic outcome measure in clinical trials of patients with osteoarthritis and rheumatoid arthritis: relative validity of scales in relation to clinical measures of arthritis severity. Med Care. 1999;37:MS23-9.

27. Prevoo ML, van't Hof MA, Kuper HH, van Leeuwen MA, van de Putte $L B$, van Riel PL. Modified disease activity scores that include twenty-eight-joint counts. Development and validation in a prospective longitudinal study of patients with rheumatoid arthritis. Arthritis Rheum. 1995:38:44-8.

28. Contreras-Yáñez I, Ponce de León S, Cabiedes J, Rull-Gabayet M, Pascual-Ramos V. Inadequate therapy behavior is associated to disease flares in patients with rheumatoid arthritis who have achieved remission with disease-modifying antirheumatic drugs. Am J Med Sci. 2010;340:282-90.

29. Contreras-Yánez I, Rull-Gabayet M, Pascual-Ramos V. Early disease activity suppression and younger age predict excellent outcome of recent-onset rheumatoid arthritis patients treated with conventional disease modifying anti-rheumatic drugs. Clin Exp Rheumatol. 2012;30:402-8.

30. de Velasco JEM, Morfin Martín J, Motta Martínez E, Colegio Mexicano de Especialistas en Ginecología y Obstetricia. Clinical practice guidelines. Study of climacteric and menopause. Ginecol Obstet Mex. 2009;77:S253-76.

31. Mäkinen $H$, Kautiainen $H$, Hannonen P, Sokka T. Is DAS28 an appropriated tool to assess remission in rheumatoid arthritis? Ann Rheum Dis. 2005;64:1410-3
32. Felson DT, Smolen JS, Wells G, Zhang B, van Tuyl LH, Funovits J, et al. American College of Rheumatology/European League Against Rheumatism provisional definition of remission in rheumatoid arthritis for clinical trials. Arthritis Rheum. 2011;63:573-86.

33. Expert Panel on Detection, Evaluation and Treatment of High Blood Cholesterol in Adults. Executive summary of the third report of The National Cholesterol Education Program (NCEP) Expert Panel on Detection, Evaluation and Treatment of High Blood Cholesterol in Adults (Adult Treatmet). JAMA. 2001;285:2486-97.

34. Alberti KG, Zimmet P, Shaw J. IDF Epidemiology Task Force Consensus Group. The metabolic syndrome - a new worldwide definition. Lancet. 2005;366:1059-62.

35. da Cunha VR, Brenol CV, Brenol JC, Xavier RM. Rheumatoid arthritis and metabolic syndrome. Rev Bras Reumatol. 2011;51:260-8.

36. Ferraz-Amaro I, González-Juanatey C, López-Mejias R, Riancho-Zarrabeitia L, González-Gay MA. Metabolic syndrome in rheumatoid arthritis. Mediators Inflamm. 2013:710928. doi:10.1155/2013/710928.

37. Karimi M, Mazloomzadech S, Kafan S, Amirmoghadami $H$. The frequency of metabolic syndrome in women with rheumatoid arthritis and in controls. Int J Rheum Dis. 2011;14:248-54.

38. Sahebari M, Goshayeshi L, Mirfeizi Z, Rezaieyazdi Z, Hatef MR, GhayourMobarhan $\mathrm{M}$, et al. Investigation of the asssociation of metabolic syndrome and disease activity in rheumatoid arthritis. Sci World J. 2011;11:1195-205.

39. La Montagna G, Cacciapuoti F, Buono R, Manzella D, Mennillo GA, Arciello $A$, et al. Insulin resistance is an independent risk factor for atherosclerosis in rheumatoid arthritis. Diab Vasc Dis Resp. 2007:4:130-5.

40. Giles JT, Allison M, Blumenthal RS, Post W, Gelber AC, Petri M, et al. Abdominal adiposity in rheumatoid arthritis: associations with cardiometabolic risk factors and disease characteristics. Arthritis Rheum. 2010;62:3173-82.

41. Mok CC, Ko GT, Ho LY, Yu KL, Chan PT, To CH. Prevalence of atherosclerotic risk factors and the Metabolic syndrome in patients with chronic inflammatory arthritis. Arthritis Care Res (Hoboken). 2011;63:195-202.

42. Zonana-Nacach A, Santana-Sahagún E, Jiménez-Balderas FJ, CamargoCoronel A. Prevalence and factors associated with metabolic syndrome in patients with rheumatoid arthritis and systemic lupus erythematosus. J Clin Rheumatol. 2008;14:74-7.

43. González-Gay MA, Llorca J, García-Unzueta MT, González-Juanatey C, De Matias JM, Martin J, et al. High-grade inflammation, circulating adiponectin concentrations and cardiovascular risk factors in severe rheumatoid arthritis. Clin Exp Rheumatol. 2008;26:596-603.

44. Rostom S, Mengat M, Lahlou R, Hari A, Bahiri R, Hajjaj-Hassouni N. Metabolic syndrome in rheumatoid arthritis: a case control study. BMC Musculoskelet Disord. 2013;14:147.

45. Crowson CS, Myasoedova E, Davis 3rd JM, Matteson EL, Roger VL, Therneau TM, et al. Increased prevalence of metabolic syndrome associated with rheumatoid arthritis in patients without clinical cardiovascular disease. J Rheumatol. 2011;38:29-35.

46. Toms TE, Panoulas VF, John H, Douglas KM, Kitas GD. Methotrexate therapy associates with reduced prevalence of the metabolic syndrome in rheumatoid arthritis patients over the age of 60 - more than just an antiinflammatory effect? A cross sectional study. Arthritis Res Ther. 2009;11:R110.

47. da Cunha VR, Brenol CV, Brenol JC, Fuchs SC, Arlindo EM, Melo IM, et al. Metabolic syndrome prevalence is increased in rheumatoid arthritis patients and is associated with disease activity. Scand J Rheumatol. 2012;41:186-91.

48. Gremese E, Ferraccioli $\mathrm{G}$. The metabolic syndrome: the crossroads between rheumatoid arthritis and cardiovascular risks. Autoimmun Rev. 2011;10:582-9.

49. González-Gay MA, Llorca J, García-Unzueta MT, González-Juanatey C, Miranda-Filloy JA, Vázquez-Rodríguez TR, et al. Anti-TNF-alpha therapy modulates resistin in patients with rheumatoid arthritis. Clin Exp Rheumatol. 2008;26:311-6

50. González-Gay MA, González-Juanatey C, Vázquez-Rodríguez TR, Miranda-Filloy JA, Llorca J. Insulin resistance in rheumatoid arthritis: the impact of anti-TNF-alpha therapy. Ann NY Acad Sci. 2010;2010:153-9.

51. Blazar BR, Whitley CB, Kitabchi AE, Tsai MY, Santiago J, White N, et al. In vivo chloroquine-induced inhibition of insulin degradation in a diabetic patient with severe insulin resistance. Diabetes. 1984;33:1133-7.

52. Dessein PH, Tobias M, Veller MG. Metabolic syndrome and subclinical atherosclerosis in rheumatoid arthritis. J Rheumatol. 2006:33:2425-31.

53. Dessein PH, Joffe BI, Veller MG, Stevens BA, Tobias M, Reddie K, et al. Traditional and non-traditional cardiovascular risk factors are associated with atherosclerosis in rheumatoid arthritis. J Rheumatol. 2005:32:435-42. 